\title{
Fluorescein angiography in chronic simple and low-tension glaucoma
}

\author{
R. A. HITCHINGS \\ Department of Clinical Ophthalmology, Institute of Ophthalmology, \\ Moorfields Eye Hospital, City Road, London, ECI \\ G. L. SPAETH \\ Wills Eye Hospital, Philadelphia, Pa, USA
}

SUMMARY Fluorescein angiograms were performed on a group of low-tension glaucoma and chronic simple glaucoma patients with similar extent of visual field loss, under standardised conditions, to see whether differences attributable to chronic intraocular pressure elevation could be detected. There was no evidence for difference in circulation times between these two groups. There was no evidence that hypoperfusion of the peripapillary choroid contributed to optic nerve hypoperfusion. Low-tension glaucoma patients demonstrated focal sector hypoperfusion of the optic nerve in every case, while the chronic simple glaucoma patients demonstrated a wide range of optic nerve fluorescence, suggesting both focal and diffuse optic nerve head hypoperfusion. It was concluded that, while focal hypoperfusion of the optic nerve may reflect susceptible vasculature at the nerve head with or without intraocular pressure elevation, diffuse hypoperfusion suggested that prolonged intraocular pressure elevation may simultaneously affect the whole of the optic nerve head. This could be a direct effect on blood vessels or a mechanical effect with secondary vascular changes.

The hallmarks of glaucomatous disease are cupping and pallor of the optic nerve head together with visual field loss and elevated intraocular pressure (IOP). The relative importance of an elevated IOP and vascular disease of the optic nerve head in the causation of cupping of the optic nerve have yet to be determined. Optic nerve head disease in chronic glaucoma may only be the result of a direct mechanical effect of elevated IOP on the neurones or glial cells (Fuchs, 1916; Smith, 1965; Emery et al., 1974; Anderson, 1975). In contrast, the glaucomatous optic nerve may reflect primary vascular or haematological disease principally affecting the optic nerve head (Drance, 1972) in a manner similar to those examples of acute anterior ischaemic optic neuropathy which are followed by an increase in volume of the optic cup (Hayreh, 1974). Finally, the glaucomatous optic nerve may be a result of vascular disease of the optic nerve secondary to an elevated IOP (Hayreh, 1970).

This paper assesses the role chronic elevation of IOP may have in the pathogenesis of glaucomatous

This study was supported in part by NIH grant no. E70067704

Address for reprints: Mr R. A. Hitchings, Moorfields Eye Hospital, City Road, London, EC1V 2PD optic nerve disease by comparing the fluorescein angiograms from eyes with similar visual field defects which were known to have either chronic simple or low-tension glaucoma.

\section{Material and methods}

The patients reported here formed part of a larger investigation utilising fluorescein angiography to study the vascular circulation of glaucomatous eyes. Cases selected for inclusion in this study fulfilled the following criteria:

(a) Visual field examination showed an arcuate scotoma, defined as a scimitar-shaped defect which extended from the blind spot to pass above or below fixation and which terminated at the horizontal meridian nasal to fixation. Patients whose visual fields revealed lesser or greater defects were not included.

(b) Glaucomatous cupping, defined as vertical cup/disc ratio of $>0.5$, together with any of the following: localised (asymmetrical) thinning of the neuroretinal rim, localised (asymmetrical) pallor of the neuroretinal rim, and a difference in the cup/disc ratios between the two eyes of $>0 \cdot 2$ diameter.

(c) Fluorescein angiography and visual field 
examination performed within one month of each other (usually on the same day). The technique employed for both investigations was the same in each case and has been fully reported elsewhere (Spaeth, 1975).

(d) Intraocular pressure of $22 \mathrm{mmHg}$ or less, both at the time of the visual field examination and immediately following the angiogram.

(e) Angiograms of good quality with frames separated by $<1.0$ second interval in the early phase of the angiogram allowing accurate determination both of circulation times and filling of the disc and peripapillary choroid. The angiographic technique and method used to determine circulation times have been fully described by Spaeth (1975). Angiograms with pseudofluorescence of the optic disc were rejected because of difficulties in interpretation.

The two groups of patients were: (a) classical chronic simple glaucoma patients with an intraocular pressure of $>21 \mathrm{mmHg}$ at the time of presentation; (b) low-tension glaucoma patients, in whom the diagnosis was confirmed by a diurnal pressure curve which documented intraocular pressures consistently $<22 \mathrm{mmHg}$, together with a normal facility of aqueous outflow. Each patient with low-tension glaucoma had a neurological examination to exclude non-ocular causes for the visual field defect. No patient had suffered a period of systemic hypotension. 18 eyes with chronic simple glaucoma and 9 eyes with lowtension glaucoma filled these criteria.

\section{Analysis of the fluorescein angiogram}

While analysing the fluorescein angiograms the following criteria were checked:

\section{TRANSIT TIMES}

(a) Retinal transit times. The time between the first appearance of dye in the central artery and its appearance in a temporal retinal vein at, or distal to, the first major tributary.

(b) Disc transit time. The time between the first appearance of the dye in the optic disc and its appearance in superficial disc veins. The disc veins could be seen as small collector channels arising from the racemose capillary network on the optic disc (Shimizu, 1974). Identification of this 'disc circulation' could be made with certainty only in well focused angiograms, having several frames in the early part of the fluorescein 'run'. Only fluorescein angiograms where this circulation could be identified were included in this study. (The racemose capillary system is visible in the pre-arterial part of the fluorescein run and disc veins are visible in the arterial phase. Visibility of the disc veins is lost in the early venous phase of the angiogram with filling of the radial epipapillary capillaries (Shimizu, 1974) which run on to the 'surface' of the disc.)

\section{FLUORESCENCE OF THE OPTIC DISC AND} PERIPAPILLARY CHOROID

Disc filling was said to have occurred when dye could be seen in the superficial disc veins $[(b)$ above], although this did not correspond with the most intense or peak fluorescence of the optic disc, which occurred seconds later. Some of the optic discs had spatial filling delays lasting for two or more frames before peak fluorescence was achieved; this was designated delayed fluorescence of (part of) the optic disc. Other patients showed areas of the disc which had not reached peak fluorescence by the late venous phase of the angiogram; this was designated hypofluorescence of the optic disc. We found that hypofluorescence occurred in three different patterns which will be described below. Hypofluorescence was thought to represent hypoperfusion of the optic disc. Hypofluorescence characteristically persisted for upwards of one minute until obliterated by late diffuse disc fluorescence. Filling of the peripapillary choroid was said to have occurred when the outline of the choroidal vessels was replaced by a diffuse choroidal fluorescence.

Delayed filling of the peripapillary choroid was said to have occurred when an area of the peripapillary choroid showed persistence of the choroidal vessel pattern for two or more frames after another area had already filled. No example of delayed filling of the peripapillary choroid persisting until the late venous phase (theoretical hypofluorescence of the peripapillary choroid) as described by Hayreh (1974) was seen.

The optic disc was divided into optic cup and neuroretinal rim, so that 3 concentric zones of cup, rim, and peripapillary choroid were identified on the angiogram and corresponding areas in these zones of normal, delayed and reduced fluorescence could be ascertained. The following were looked for: (1) Areas of disc hypofluorescence; (2) areas of delayed peripapillary choroidal filling occurring next to areas of disc hypofluorescence.

\section{Results}

Intraocular pressures and systemic blood pressure at the time of the angiogram are listed in Tables 1 and 2 respectively, retinal and disc transit times are listed in Tables 3 and 4 respectively. There was no major difference between the 2 groups for any of these parameters.

Three patterns of hypofluorescence of the optic disc 
Table 1 Intraocular pressure at the time of the angiogram

\begin{tabular}{llll}
\hline & $\begin{array}{l}\text { Mean IOP } \\
(\mathrm{mmHg})\end{array}$ & $\begin{array}{l}\text { Range } \\
(\mathrm{mmHg})\end{array}$ & $\begin{array}{l}\text { Median } \\
(\mathrm{mmHg})\end{array}$ \\
\hline Chronic simple glaucoma & 17.0 & $11-22$ & $18 \cdot 0$ \\
Low-tension glaucoma & 18.0 & $14-22$ & 18.0 \\
\hline
\end{tabular}

Table 2 Blood pressure at the time of the angiogram

\begin{tabular}{llll}
\hline & $\begin{array}{l}\text { Mean BP } \\
(\mathrm{mmHg})\end{array}$ & $\begin{array}{l}\text { Range } \\
(\mathrm{mmHg})\end{array}$ & $\begin{array}{l}\text { Median } \\
(\mathrm{mmHg})\end{array}$ \\
\hline Chronic simple glaucoma & $127 / 79$ & $96 / 63-160 / 90$ & $120 / 80$ \\
Low-tension glaucoma & $130 / 82$ & $120 / 70-154 / 90$ & $122 / 80$ \\
\hline
\end{tabular}

Table 3 Retinal transit times

\begin{tabular}{llll}
\hline & $\begin{array}{l}\text { Mean } \\
(\mathrm{sec})\end{array}$ & $\begin{array}{l}\text { Range } \\
(\mathrm{sec})\end{array}$ & $\begin{array}{l}\text { Median } \\
(\mathrm{sec})\end{array}$ \\
\hline Chronic simple glaucoma & 1.7 & $1.1-4.4$ & 2.0 \\
Low-tension glaucoma & 1.6 & $0.4-2.6$ & 1.4 \\
Normal subjects & $2.0^{*}$ & & \\
\hline
\end{tabular}

*Figures from Spaeth, 1975

Table 4 Disc transit times

\begin{tabular}{llll}
\hline & $\begin{array}{l}\text { Mean } \\
(\mathrm{sec})\end{array}$ & $\begin{array}{l}\text { Range } \\
(\mathrm{ser})\end{array}$ & $\begin{array}{l}\text { Median } \\
(\mathrm{sec})\end{array}$ \\
\hline Chronic simple glaucoma & 1.6 & $0 \cdot 7-61$ & $1 \cdot 2$ \\
Low-tension glaucoma & 1.0 & $0.3-2.6$ & 0.7 \\
Normal subjects & $1.4 *$ & & \\
\hline
\end{tabular}

*Figures from Spaeth, 1975

could be seen. It must be emphasised that these patterns of optic disc hypofluorescence will only be seen on well-focused angiograms. These patterns have been called sector, patchy, and extensive. Sector hypofluorescence referred to a wedge of hypofluorescence extending from the outer edge of the neuroretinal rim towards the centre of the disc involving the adjacent part of the optic cup, the remainder of the optic disc appearing to fluoresce in a normal fashion (Fig. 1). Patchy hypofluorescence described optic discs with two or more areas of neuroretinal rim hypofluorescence separated by apparently normally fluorescing areas and associated with variable hypofluorescence of the optic cup (Fig. 2). Extensive hypofluorescence referred to a single area of hypoperfusion of the neuroretinal rim together with hypofluorescence of the entire optic cup (Figs. 3 and 4). The incidence of the various patterns of optic disc hypoperfusion in the 2 groups may be seen in Table 5. Whereas 'normal' fluorescence (Fig. 5) and all 3 patterns of hypofluorescence were seen in the eyes with chronic simple glaucoma, sector hypofluorescence only was seen in patients with low-tension glaucoma.

The results of comparing areas of delayed peripapillary choroidal filling with areas of optic disc hypofluorescence may be seen in Table 6. No difference was apparent between the 2 groups. Delayed filling of the peripapillary choroid was not preferentially sited adjacent to hypofluorescent areas of the neuroretinal rim.

The peripapillary choroidal filling delay did not persist for more than 3.5 seconds in any case.

Table 5 Hypofluorescence of the optic disc

\begin{tabular}{lll}
\hline & Pattern of hypofluorescence & $\begin{array}{l}\text { No. of } \\
\text { eyes }\end{array}$ \\
\hline 1. Chronic simple glaucoma & Sector hypofluorescence & 4 \\
& Patchy hypofluorescence & 4 \\
& Extensive hypofluorescence & 9 \\
& Normally fluorescing disc & 1 \\
2. Low-tension glaucoma & Sector hypofluorescence & 9 \\
\hline
\end{tabular}

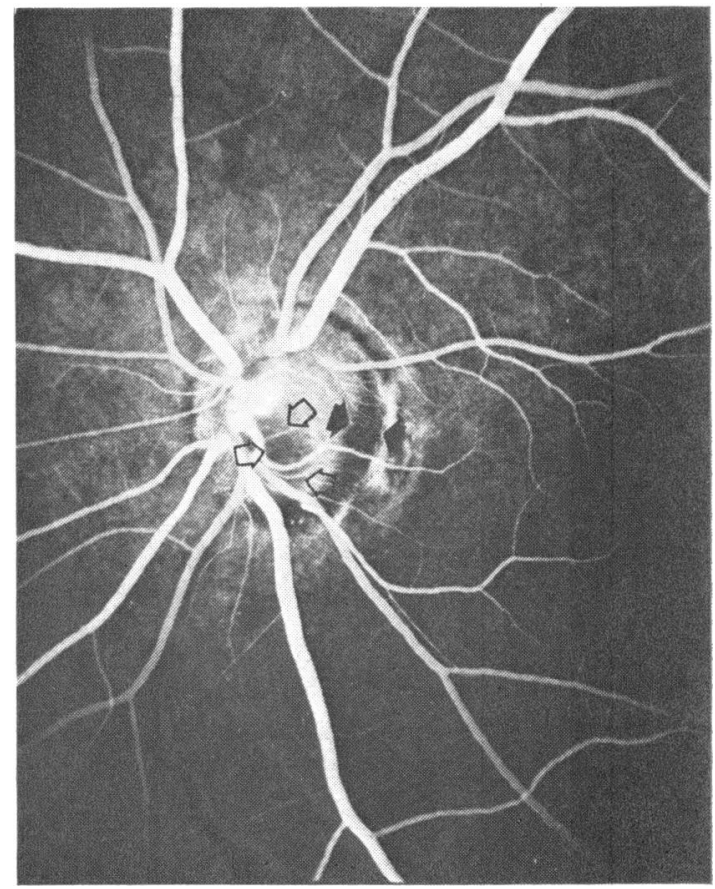

Fig. 1 SeCtOR HYPOFLUORESCENCE of the optic disc, seen in the inferotemporal quadrant (outlined by hollow arrows). Elsewhere the optic disc appears to fluoresce normally. Care must be taken to distinguish hypofluorescence of the optic disc from 'masking' caused by peripapillary pigment (solid arrows) 


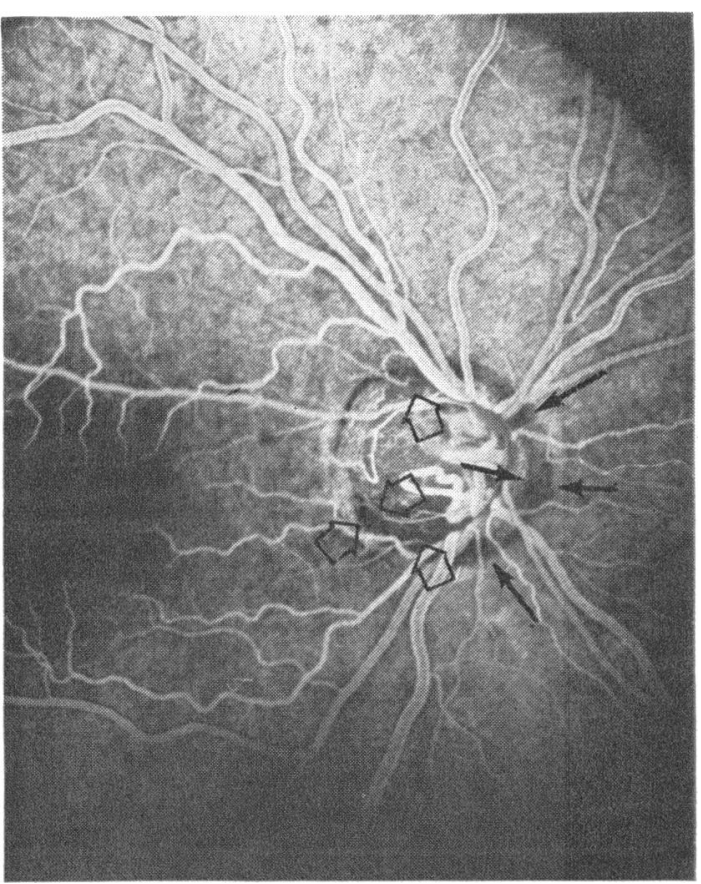

Fig. 2 PATCHY HYPOFLUORESCENCE of the neuroretinal rim (hollow arrows) associated with hypofluorescence of part of the optic cup. Hypofluorescence from peripapillary pigment is also seen (solid arrows)

\section{Discussion}

This investigation reports on the use of fluorescein angiography to contrast the papillary and peripapillary circulations in 2 groups of glaucoma patients. For the purposes of discussion it should be emphasised that the 2 groups were similar in every respect including the type of field defect, the presence of glaucomatous cupping, and intraocular pressure $\leqslant 22 \mathrm{mmHg}$ at the time of examination. The factor which separated the 2 groups was a

Table 6 Correlation between delayed choroidal filling and disc hypofluorescence

\begin{tabular}{llll}
\hline & $\begin{array}{l}\text { Disc hypo- } \\
\text { fuorescence } \\
\text { with adjacent } \\
\text { choroidal filling } \\
\text { delay (ACFD) }\end{array}$ & $\begin{array}{l}\text { Disc hypo- } \\
\text { fluorescence } \\
\text { without } A C F D\end{array}$ & No .4CFD \\
\hline $\begin{array}{l}\text { 1. Chronic simple } \\
\text { glaucoma }\end{array}$ & 7 eyes & 7 eyes & $\begin{array}{l}\text { 4 eyes (1 with } \\
\text { circum- } \\
\text { papillary } \\
\text { choroidal } \\
\text { atrophy) }\end{array}$ \\
$\begin{array}{l}\text { 2. Low-tension } \\
\text { glaucoma }\end{array}$ & 3 eyes & 5 eyes & 1 eye \\
\hline
\end{tabular}

total lack of history of raised pressure in those eyes designated 'low-tension glaucoma', while in the eyes of the other group there was a well-documented history of long-standing elevation of IOP. Furthermore, the presence of normal tonographic values in the eyes diagnosed as low-tension glaucoma suggested that they were not, in fact, cases of 'burnt out' glaucoma. It was felt that any differences seen in the circulations studied would therefore be attributable to the only known difference between these 2 groups of patients, namely, that the group designated chronic simple glaucoma had had welldocumented elevation in intraocular pressure.

Conditions of study were standardised as far as possible. Care was taken to ensure that intraocular pressures were within normal levels as it is known that abnormally high intraocular tensions may induce a change in the fluorescein angiogram that disappears when the IOP returns to normal (Best et al., 1972; Spaeth, 1975). Similarly, care was taken to ensure that intraocular pressure was not elevated at the time of the visual field examination, as this might have affected the nature of the scotoma (Gafner and Goldmann, 1955). Repeat angiographic studies had shown that circulation times and filling patterns were reproducible (Spaeth, 1975).

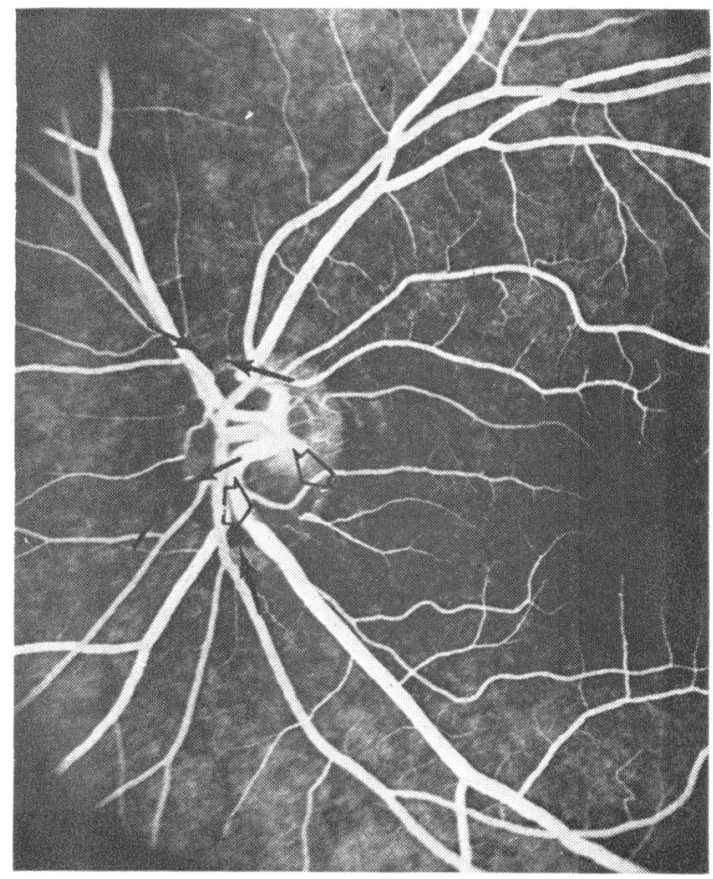

Fig. 3 EXTENSIVE HYPOFLUORESCENCE of the optic cup togeether with localised hypofluorescence of the neuroretinal rim (hollow arrows). Hypofluorescence from peripapillary pigment is also seen (solid arrows) 


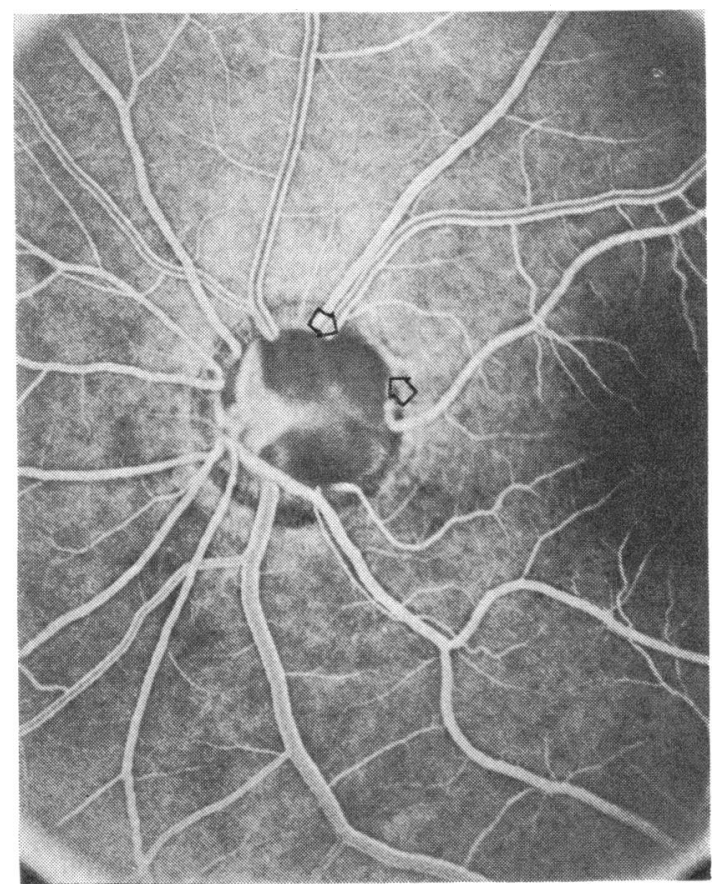

Fig. 4 EXTENSIVE HYPOFLUORESCENCE of the optic c:ip together with localised hypofluorescence of the neuroretinal rim (hollow arrows). Hypofluorescence from peripapillary pigment is also seen (solid arrows)

The laminar and prelaminar regions of the disc are thought by some to receive a portion of their blood supply from the adjacent peripapillary choroid on the basis of anatomical (Hayreh, 1969; Henkind and Levitsky, 1969; Francois and Neetens, 1972; Ernest, 1975), and fluorescein studies (Ernest and Potts, 1968; Hayreh, 1970; Best et al., 1972). Poor autoregulation of choroidal blood flow may render the peripapillary choroidal circulation more susceptible to elevated intraocular pressures (Alm and Bill, 1973) when the blood flow to the optic disc would be diminished. Some observational support for this hypothesis has been provided by Hayreh (1974), who noted so-called peripapillary choroidal hypofluorescence, later reversing to delayed peripapillary fluorescence, in the early stages of anterior ischaemic optic neuropathy. Hayreh (1974) suggested that a similar sequence of events was the cause of optic nerve hypoperfusion and cupping. If this sequence of events was responsible for optic disc ischaemia in glaucomatous eyes, areas of focal disc hypoperfusion, visible as hypofluorescence on fluorescein angiography, should lie adjacent to regions of delayed peripapillary choroidal filling, providing these regions do not undergo spatial variation with time.
In studies reported elsewhere (Hitchings and Spaeth, 1976; Spaeth, 1975) the authors concluded that areas of peripapillary filling delay were remarkably constant in shape and site during observational periods of up to 4 years in duration.

Areas of peripapillary choroidal filling delay did not persist for more than 3.5 seconds. This delay was no greater than has been found in the normal population (Spaeth, 1975). These areas of filling delay were not found most frequently adjacent to areas of neuroretinal rim hypoperfusion, nor was there any difference between the 2 groups of patients. There was no evidence that focal peripapillary hypoperfusion played any part in the pathogenesis of disc hypofluorescence in either of the 2 groups of patients in this study.

There was no evidence for any difference in circulation times between the 2 groups of patients. Nor was there systemic hypotension in the patients with low-tension glaucoma. No patient had had an episode of acute systemic hypotension that might have precipitated the field loss (Drance, 1972). These findings are slightly surprising in view of the reports that patients with low-tension glaucoma have a higher incidence of haematological, biochemical, and vascular disease and a lower systemic blood pressure than patients with chronic simple

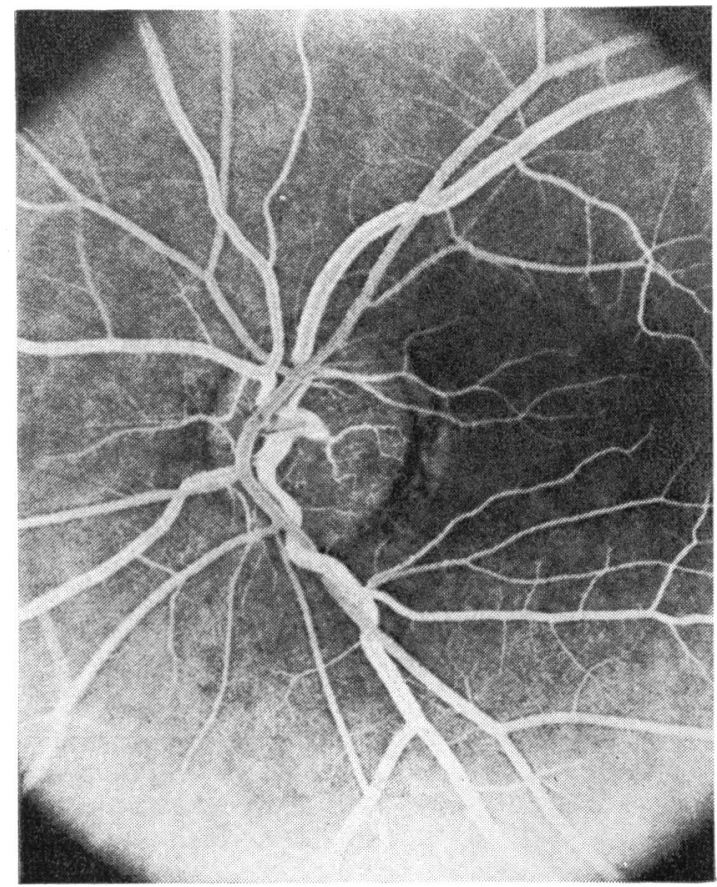

Fig. 5 NORMAL FLUORESCENCE in an eye with an upper arcuate scotoma 
glaucoma (Drance, 1972; Leighton and Phillips, 1972; Winder et al., 1974). There may be similarity between patients reported here and those of Boghen and Glaser (1975), who noted that in patients with acute ischaemic optic neuropathy the incidence of vascular and haematological disease was similar to that occurring in an age and sex matched group of normal subjects.

Hypofluorescence of the neuroretinal rim rather than hypofluorescence of the optic cup has been found to correspond with areas of field loss (Spaeth, 1975; Hitchings and Spaeth, 1976). These angiographic pictures of papillary hypofluorescence are reproducible, they persist despite long-term 'control' of intraocular pressure, and do not seem to 'improve' with time (Spaeth, 1975). In this series the arcuate field defect was associated with hypofluorescence of the neuroretinal rim in all bar one patient (Fig. 5). This patient, however, had 'normal' fluorescence of the optic disc, and it must be assumed that at this stage no changes in the vascular network of the optic nerve, detectable by optic disc angiography, had occurred.

Four patients had small patches of hypofluorescence on the neuroretinal rim in areas not corresponding with the visual field defect. Repeat angiograms confirmed these defects. It is likely that these hypofluorescent areas represent hypoperfusion and reflect reduced neuronal function. The resultant field defects must have been too small to be noticed by the patient with the method of Goldmann field testing employed in this study (Spaeth, 1975).

The 2 groups of patients differed in that only those patients in the group labelled "chronic simple glaucoma' were known to have had chronic elevation of intraocular pressure. The fluorescein angiograms differed in that all patients with lowtension glaucoma showed sector hypofluorescence, while a more varied pattern, including sector hypofluorescence was seen in the eyes that had chronic simple glaucoma. Begg et al. (1972) also noted sector hypofluorescence in a group of 10 patients, each with an arcuate scotoma, 3 of whom were diagnosed as low-tension glaucoma. Sector hypofluorescence is explained by non-perfusion of the radial centrepetal prelaminar arteries, described by Hayreh (1970). In some individuals these vessels would appear particularly vulnerable, localised nonperfusion occurring in the absence of elevated intraocular pressure. The resultant glaucomatous cupping with field loss is diagnosed as low-tension glaucoma. Similar vascular non-perfusion occurs in some patients with chronic simple glaucoma. However, eyes with chronic simple glaucoma may demonstrate a far greater degree of papillary hypofluorescence (13 out of 18 in this series). This suggests chronic elevation of intraocular pressure may affect blood vessels over the whole area of the disc, either directly, or indirectly following loss of neurones or glia.

We thank Mr A. C. Bird and Mr R. J. H. Smith for helpful advice and criticism; Mr L. W. Bell took the photographs; Miss $M$. Warwick typed the manuscript.

\section{References}

Alm, A., and Bill, A. (1973). Ocular and optic nerve blood flow and increased intraocular pressures in monkeys. (Macaca irus): A study with radioactively labelled microspheres including flow determination in brain and some other tissue. Experimental Eye Research, 15, 15-29.

Anderson, D. R. (1975). Pathogenesis of glaucomatous cupping: A new hypothesis, in Symposium on Glaucoma, p. 81. St. Louis, C. V. Mosby.

Begg, I. S., Drance, S. M., and Goldman, H. (1972). Fluorescein angiography in the evaluation of focal circulatory ischaemia of the optic nerve head in relation to the arcuate scotoma in glaucoma. Canadian Journal of Ophthalmology, 7, 68-74.

Best, M., et al. (1972). Fluorescein angiography during induced ocular hypertension in glaucoma. British Journal of Ophthalmology, 56, 6-12.

Boghen, D. R., and Glaser, J. S. (1975). Ischaemic optic neuropathy: The clinical profile and natural history. Brain, 98, 689-708.

Drance, S. M. (1972). Some factors involved in the production of low-tension glaucoma, in The Optic Nerve, ed. C. J. Cant, p. 339. St. Louis, C. V. Mosby.

Emery, J. M., et al. (1974). The Lamina Cribosa in normal and glaucomatous eyes. Transactions of the American Academy of Ophthalmology and Otolaryngology, 78, 290-297.

Ernest, T., and Potts, A. M. (1968). Pathophysiology of the distal portion of the optic nerve II. Vascular relationships. American Journal of Ophthalmology, 66, 380-387.

Ernest, J. T. (1975). Pathogenesis of glaucomatous optic nerve disease. Transactions of the American Ophthalmological Society, 3, 366-388.

Francois, J., and Neetens, A. (1972). Fine angio-architecture of the optic nerve, in The Optic Nerve, ed. C. J. Cant, p. 28. St. Louis, C. V. Mosby.

Fuchs, E. (1916). Ueber die Lamina Cribrosa (Trans. Henderson, E. E.), 1918. British Journal of Ophthalmology, 2, 50-53.

Gafner, F., and Goldman, H. (1955). Experimentelle untersuchengen uber den zusammenhang von augendrucksleigerung und cesichtsfeldschadigung. Ophthalmologica (Basel), 130, 357-377.

Hayreh, S. S. (1969). Blood supply of the optic nerve head and its role in optic atrophy, glaucoma and oedema of the optic disc. British Journal of Ophthalmology, 53, 721-748.

Hayreh, S. S. (1970). Pathogenesis of visual field defects. British Journal of Ophthalmology, 54, 289-311.

Hayreh, S. S. (1974). Pathogenesis of cupping of the optic disc. British Journal of Ophthalmology, 58, 863-876.

Henkind, P., and Levitsky, M. (1969). Angio-architecture of the optic nerve: I-The papilla. American Journal of Ophthalmology, 68, 979-996.

Hitchings, R. A., and Spaeth, G. L. (1976). Fluorescein angiography in glaucoma, in Vision and Circulation, ed. C. J. Cant, p. 201-216. London, Henry Kimpton. 
Leighton, D. A., and Phillips, C. I. (1972). Systemic blood pressure in open-angle glaucoma, low-tension glaucoma and the normal eye. British Journal of Ophthalmology, 56, 447-453.

Shimizu, K. (1974). Fluorescein angiography of the ocular fundus, in Fluorescence of the Optic Disc, p. 79. Stuttgart, G. Thieme.

Smith, R. J. H. (1965). Clinical Glaucoma, p. 155. London, Cassel.
Spaeth, G. L. (1975). Fluorescein angiography: its contribution towards understanding the mechanisms of visual loss in glaucoma. Transactions of the American Ophthalmological Society, 63, 491-553.

Winder, A. F., et al. (1974). Biochemical abnormalities associated with ocular hypertension and low-tension glaucoma. Transactions of the Ophthalmologicial Societies of the United Kingdom, 94, 518-524. 